\title{
GÓMEZ NAVARRO, Soledad, Mirando al cielo sin dejar el suelo: Los Jerónimos cordobeses de Valparaíso en el Antiguo Régimen
}

Estudio Preliminar y Edición Crítica del libro Protocolo de la comunidad. Madrid, Visión Libros, 2014. 822 pp. ISBN: 978-84-9886-763-3

Durante las últimas cuatro décadas se ha constatado la aparición de una ingente producción historiográfica sobre los estudios de la Historia de la Iglesia en España aunque la renovación metodológica no siempre ha estado a la misma altura. El claustro hispano ha sido objeto de análisis para conocer las bases socioculturales e institucionales mientras se ha profundizado con detalle en aspectos relativos a la vida cotidiana y la espiritualidad, la organización interna de las Órdenes, la incidencia de Trento en las comunidades de religiosos y religiosas, la economía y sus rentas, las relaciones con el poder político e incluso la actividad artística y cultural de las órdenes. Contamos con numerosos estudios pero no están lo suficientemente sistematizados como se indicaba, hace ahora una década, en la síntesis colectiva, El peso de la Iglesia. Cuatro siglos de Órdenes Religiosas en España, editada bajo la dirección de Enrique Martínez Ruiz, centrada en la iglesia y en sus múltiples vertientes como institución social y de poder.

Soledad Gómez Navarro, como indica en la introducción del Protocolo de los jerónimos cordobeses de Valparaíso, nos prepara para la digestión de una completa y detallada edición crítica de una serie de textos inéditos desde antes de la fundación del cenobio, es decir, entre 1405-1408 y hasta poco antes de la desamortización de Mendizábal, en 1831, y no solo intramuros, por los múltiples datos y referencias que relacionan de una u otra forma a Valparaíso con la ciudad y el reino de Córdoba.

Editado por Visión Libros y en cuya coedición figuran el colegio Notarial de Andalucía y el Instituto Escurialense de Investigaciones Históricas y Artísticas, la obra Mirando al cielo sin dejar el suelo se centra en el Protocolo o Tumbo de los jerónimos sobre el que realiza una magnífica edición crítica. La fuente tiene un valor extraordinario por tratarse de un libro único e irrepetible que al margen de su enorme valor económico y social ofrece un singular potencial jurídico y administrativo. La edición recoge el esfuerzo en la investigación de largos años de trabajo de la profesora Soledad Gómez quien tiene una excelente trayectoria y ocupa ya un lugar propio en los estudios de la Historia de la Iglesia. Gran conocedora de las últimas voluntades y de la experiencia del morir en la España del Antiguo Régimen, ya editó algunas obras sobre eclesiásticos 
de relieve como el proceso del arzobispo Carranza o la misión del cardenal Salazar o sobre fuentes documentales del patrimonio monástico y conventual.

La Ordo Sancti Hieronymi, orden de San Jerónimo (OSH), tuvo una implantación exclusivamente peninsular y una estrecha vinculación con la Casa de Trastámara desde su aprobación por el Papa Gregorio XI en 1373 con la bula Salvatoris humanis generis. La fundación de Valparaíso se produjo a comienzos del siglo XV gracias a la mediación del jerónimo portugués Fray Vasco o Basco, quien decidía en 1405 trasladarse a España desde el reino luso, tras ayudar en la fundación de dos conventos. Por esas fechas y, tras establecer distintos contactos con la nobleza local, se canalizan las primeras donaciones para el levantamiento de la capilla, el altar y el coro para el culto. En 1440, Juan II de Castilla, acogía bajo su amparo y protección a todos los monjes del monasterio y sus sirvientes, es decir, lo dota de un carácter «real».

El importante patrimonio rústico de Valparaíso siguió creciendo hasta despertar, sin duda, los afanes desamortizadores de los gobernantes. En 1835 los Jerónimos fueron desposeídos de sus 48 monasterios y unos mil monjes fueron exclaustrados. Sin embargo, el infausto decreto de 30 de agosto propició la redacción de un inventario en el que figurasen todos los bienes muebles hallados en el monasterio. En el archivo de san Jerónimo se encontró un libro de enorme tamaño de pergamino, llamado Tumbo, que contenía, copiados a la letra, las escrituras y privilegios de sus pertenencias, siendo redactado, según las evidencias que aporta la autora, entre 1772 y 1831.

La voluminosa edición que presenta la profesora Soledad Gómez supone un indudable esfuerzo para aportar una obra detallada, rigurosa y con coherencia interna sobre la Orden Jerónima. De alguna forma es un doble esfuerzo al presentarnos dos monografías en una: la del estudio preliminar y la edición crítica de un valioso manuscrito para el conocimiento de la Orden jerónima. Con un concienzudo estado de la cuestión, se analiza una fuente que recoge de una forma sistemática datos y aportaciones que resultan fundamentales para el conocimiento de la historia económica, social, política y cultural del monasterio de Valparaíso y, por ende, de la ciudad y el reino de Córdoba en la Edad Moderna.

Valparaíso no se vio en exclusiva favorecido por el poder real. A comienzos del siglo XVI había en España más de una treintena de monasterios jerónimos y su enorme potencial económico se extendía por la mayor parte del suelo peninsular, abarcando los de Guadalupe, Yuste y El Escorial. Gracias a beneficios y privilegios de Papas, donaciones regias y de otros distinguidos magnates de la nobleza el monasterio se situó -como señala Soledad Gómez- «bajo las alas del poder» muy especialmente durante la segunda mitad del siglo XV.

En el debe, como tiene toda fuente documental, el protocolo no parece el instrumento más adecuado para conocer la sociología y algunos aspectos de la dimensión económica de san Jerónimo de Valparaíso. Con enorme paciencia monacal, aquella que garantiza como en los claustros el orden y el silencio, la autora se eleva por encima de las asiduas oraciones y rigurosas penitencias de los monjes, mirando al cielo, para trasladarnos el cenobio a una realidad con enormes implicaciones mundanas sin dejar el suelo superando la santificación de las horas y las solemnidades eremitarias. 
Con todo, el estudio preliminar y la edición crítica, junto a la relación de fuentes, bibliografía, anexos e índices resultan de enorme utilidad para conocer la historia de los jerónimos cordobeses desde comienzos del siglo XV y hasta la tercera década del Ochocientos. No cabe duda que Valparaíso ejerció funciones de tipo cultural, pastoral o religiosa, asistencial o benéfica, educativa, social e incluso política, en tanto mantuvo unas políticas de colaboración estrechas con el poder. Por ello, su consulta va a resultar de enorme utilidad para docentes y discentes, instrumento de trabajo útil para futuras investigaciones $\mathrm{y}$, sin duda, una de las más sólidas monografías escritas hasta el momento sobre los Jerónimos españoles.

Porfirio Sanz Camañes

Universidad de Castilla-La Mancha 